\title{
Training in psychiatry in Europe
}

\section{Fiona Caldicott}

It is appropriate to be writing about psychiatric training in Europe as the joint meeting between the Royal College of Psychiatrists and the Association of European Psychiatrists is being planned for July 1996.

At the Annual Meeting of the College in Brighton in 1991, a seminal meeting took place between representatives of several European countries at the instigation of $\mathrm{Dr}$ James Birley, President of the College between 1987 and 1990. The Monospecialist Section of Psychiatry of the European Union of Medical Specialists had been relatively inactive, and it was decided to revive it. A few months later a meeting was held in Brussels. Dr Paul Lievens was elected Chairman and I was elected Secretary of the Section.

In the following year guidance was received from the UEMS concerning the establishment of Boards by each Section which would be responsible for the consideration of training in the speciality. The European Board of Psychiatry was set up in the Autumn of 1992, and like the Section has met twice a year since its establishment.

In order to keep costs of the committees to a minimum each country nominates two individuals as its representatives, meeting the requirement for the Board to have on it an academic from the speciality and a specialist who is largely involved in service provision. We have taken the opportunity to visit a different country in turn, and spend a day before the meetings seeing the local service and hearing about arrangements for training.

Following vigorous lobbying from Germany, child psychiatrists asked the UEMS to approve a separate Section, and as the speciality is recognised in more than eight EU countries this was agreed. Unfortunately this has meant that from the outset training in psychiatry has been considered in isolation from training in child and adolescent psychiatry.

Most countries in the European Union have been represented regularly at the meetings, as has Norway. More recently we have welcomed observers from Bulgaria and Slovenia.

In the tradition of the College we encouraged the Collegiate Trainees Committee of the College to facilitate a meeting of European trainees in 1992. They now meet twice a year and we invite the trainee representative of the country where the meeting is taking place to join us. In accordance with the recommendations of the UEMS, a representative of the Permanent Working Group of trainees also attends.

The Board has discussed training in psychotherapy, which is much more developed in some countries than others. It has considered the UEMS draft Charter for training in all specialities, and commented on it from the perspective of psychiatry.

Most importantly, much work has been done in recent months to reach agreement on a 'core' training in psychiatry, which in the view of their representatives, all member countries will wish to support even if at the moment they cannot provide some components.

It has been extremely rewarding work even though there is such variation in the way that psychiatric training is provided in Europe. To take the length of training as an example, this varies from four years in Greece and Portugal to six to seven years in Ireland and the UK. Similar work has been undertaken in the Section for Child Psychiatry.

It is important to note that while child psychiatry is recognised in eight European countries, the other specialities of the UK and Ireland (forensic psychiatry, learning disability psychiatry, old age psychiatry and psychotherapy) are not.

While these discussions have been taking place radical changes have been occurring in the UK and Ireland. The establishment of a so-called market in health care provision in the UK has had a marked effect on the delivery of postgraduate medical and dental education. At a time of increasingly rapid changes in medical technology, the curricula and training programmes for junior doctors and the requirements for continuing professional development for consultants and other career grades need prompt and appropriate modification so that patient care can be of high quality, and where possible of proven cost-effectiveness.

But in the view of the European Parliament the UK has not been complying with the European 
Directives concerning, in particular, the issuing of certificates which required a relatively short duration of training but did not lead to eligibility for appointment as a consultant in the NHS here. This led to the start of infraction proceedings against the UK Government.

In 1992 the Chief Medical Officer, (then) Dr Kenneth Calman, set up a high-level group to consider specialist training in the UK. It reported in 1993 and the Government accepted its recommendations: the Medical Royal Colleges were to publish their curricula and entry criteria for higher specialist training and programmes which should be of such a length that when satisfactorily completed would denote eligibility for independent practice as a consultant. In many instances where career progress had been delayed by hurdles created by an imbalance between junior and senior training grades, they should be shorter. The registrar and senior registrar grades should be combined to remove one hurdle to the efficient completion of training. Completion of specialist training would be defined by the award of a certificate and the General Medical Council (GMC) should produce and publish lists of trained specialists.

Implementation of these requirements is now almost complete. Structured training programmes have been published (available from the Joint Committee of Higher Psychiatric Training) and entry criteria agreed. In psychiatry these are: three years in general professional or basic specialist training, success in the Membership examinations and a competitive interview. The College has successfully argued for the merger of senior house officer and registrar posts in psychiatry with the current senior registrar grade becoming the new specialist registrar grade, for higher specialist training. This recognises the nature of registrar training, usually providing experience first on-call and where general professional training is occurring. Higher specialist training in the speciality of choice and suitability occurs post MRCPsych.

A Specialist Medical Order was approved by Parliament on 12 January 1996. It established a new competent authority, alongside the General Medical Council, which will issue certificates of completed specialist training on the advice of each College to trainees, and ensure that the Colleges meet the legal requirements for specialist training under European Union Directives. Established consultants will need to have their names on the GMC's specialist lists and the GMC are shortly to circulate details of how consultants can be registered.

In Ireland, the Tierney Report is having a similar impact as those responsible consider equivalent changes. A close relationship between the Joint Committee on Higher Psychiatric Training and the Irish Psychiatric Training Committees continues and should ensure that the current movement of higher trainees can persist. It is hoped that existing reciprocity, based on a long and valued tradition between other Irish and UK Colleges can be preserved as the competent Authorities in each country recognise equivalent training in the other.

While it may appear from the description of these developments, which have required a great deal of work, as if movement of psychiatric trainees and specialists within Europe will occur more frequently, considerable doubts about this remain. The lack of recognition of several UK specialities in psychiatry will probably mean that trainees wishing to work in continental Europe will need to obtain a certificate in general or child psychiatry.

As a language based speciality, markedly influenced by social factors, psychiatry is not an ideal choice for those who wish to move freely around Europe. The evidence thus far is that a relatively small number of trainees wish to move for some part of their training, and return home for specialist practice. Very few stay as consultants or in other career grade posts. The European Board is considering the possibility of exchanges for those who would like to undertake them. Meanwhile we must trust that the agreement on a 'core training' for Europe and the 'Calman' changes will improve psychiatric training, and therefore patient care, on this continent. 